\title{
Palliative care: Benefits when included early to treat cancer
}

\section{Cuidados paliativos: beneficios cuando se incluyen tempranamente para tratar el cáncer}

\begin{abstract}
Rocío Candelario Santiago ${ }^{a}$, Edú Ortega Ibarra ${ }^{b}$, Ilse Haide Ortega Ibarrac ${ }^{c}$
Abstract:

This paper aims to understand palliative care (PC) when included as part of the treatment for patients with cancer and when there is no need to wait for the person to be in an advanced or terminal stage of the disease. Palliative care is considered as the care required by patients living critical stages of life. Therefore, palliative care should be included from the diagnosis phase of the disease in order to go hand in hand with treatment. This situation is of great importance, because as we are human beings, we have emotional, social, and spiritual needs so that we perceive ourselves in a wholesome way.
\end{abstract}

\section{Keywords:}

Palliative care, cancer, treatment, nursery

\section{Resumen:}

Este trabajo tiene como objetivo comprender los cuidados paliativos (CP) cuando se incluye parte del tratamiento del paciente con cáncer y no hay necesidad de esperar a que la persona se encuentre en una etapa avanzada o terminal de la enfermedad. Los cuidados paliativos se consideran los cuidados que requieren los pacientes que viven etapas críticas de la vida. Por tanto, los cuidados paliativos deben incluirse desde la fase de diagnóstico de la enfermedad para ir de la mano del tratamiento. Esta situación es de gran importancia, porque somos seres humanos, tenemos necesidades emocionales, sociales y espirituales para que nos percibamos de manera integral y total.

\section{Palabras Clave:}

Cuidados paliativos, cáncer, tratamiento, enfermería

\section{INTRODUCTION}

It is very well known that most treatments, not only for people with cancer, do not include Palliative Care (PC) in the diagnostic phase. Thus, PC should not only be included in terminal diseases, but also in the onset of diseases. ${ }^{1-3}$

This paper shows that PC is very important from the very early stages of the disease, which should be considered in order to analyse why PC should be included in this phase. The articles mentioned in this paper have been selected for the variables of interest, such as palliative care, people with cancer and inclusion in the early stages. However, it should be mentioned that there are very few studies exploring this aspect, which is worrisome.
Literature searches were conducted for studies on the topic that generated interest from those presented during the 38th Annual Oncology Nursing Meeting, held in 2021, which was derived from the topic "Benefits of including early palliative care for people with advanced cancer". ${ }^{4-6}$

Most of these studies focus on the terminal part of life, trying to consider the person as a unique and an unrepeatable being, with emotions, feelings and interpersonal relationships that will have human responses according to their characteristics. To begin with, we deal with some situations that can redirect the result of palliative care. Then, we will engage in a critical reflection as a result of the evidence found in the articles and take up the core part of palliative care to improve quality care people's lives.

\footnotetext{
${ }^{a}$ Specialty of Nursing in Oncology (Student) at Universidad Nacional Autónoma de México. Research Professor at Universidad del Istmo (academic license). https://orcid.org/0000-0002-6523-5922,Email: rocio_cs@bizendaa.unistmo.edu.mx

b, Corresponding autor. Universidad del Istmo, https://orcid.org/0000-0002-6504-7366, Email: eoi@ bizendaa.unistmo.edu.mx c Universidad del Istmo, https://orcid.org/0000-0002-1104-2949, Email: ihoi@bizendaa.unistmo.edu.mx
} 
Thus, the role of the nursing staff in relation to the integral care of people with cancer. ${ }^{1-6}$

As mentioned before, this paper aims to emphasize the importance of including palliative care from the diagnosis phase of the disease by taking into account the conditions that people have at their disposal, and the factors that may or may not contribute to access to palliative care, as well as reflecting, deepening and analysing the relationship that health personnel play in this topic of interest.

\section{ARGUMENTATIVE SECTION}

Cancer is one of the chronic diseases that is one of the leading causes of death worldwide and in Mexico it is not the exception. The cancers with the highest incidence are: breast cancer, thyroid, cervical, testicular, colon, non-Hodgkin's lymphoma, ovarian, among others, which have become a concern for the health system. All of this suggest less emphasis on prevention, and, in addition, the lack of interest of people on their health. ${ }^{1}$

When a person is diagnosed with a disease, death is the first thing that springs to his or her mind and he or she starts experiencing anguish, fragility, vulnerability and emotions that can contribute to his or her physical decline. This fact is very understandable, because people do not want to hear of death, and the simple situation of knowing that they are ill, makes them mourn for loss of health. This is where people start to feel vulnerable, because they are afraid that their lives are finite.

Therefore, when people know or hear the word "cancer", immediately they associate it with "death", as they experience a process of denial, perhaps frustration, grief, hopelessness and they feel threatened by this disease. These are the reasons why Palliative Care (PC) is of great importance. This simple fact must be special enough to generate a close relationship between the health personnel and sick people, constituting an essential element to complement the therapeutic treatment.

Now, what does palliative care mean? According to the World Health Organization (WHO), palliative care is defined as "those approaches that improve the quality of life for patients and families facing life-threatening diseases by easing the pain and other symptoms and providing psychological and spiritual support since the very first diagnosis to the end of life and during mourn". Also, the WHO claims that PC must be given from the moment of diagnosis, so a reflection on this importance begins. ${ }^{2}$ Etymologically the word "palliative" comes from the verb palliare, which means mantle or protection. Thus, Sampaio states that this word has acquired many meanings such as: make less hard, remedy, calm or relieve and that PC is based on this notion. He also points out that the concept of PC requires early identification, assessment and treatment of pain and any other physical, psychosocial and spiritual problems. Hence, care includes all aspects of the human being, but focusing on the last two: the psychosocial and spiritual aspects. ${ }^{3}$

It is important for the health staff to show interest, knowledge, professionalism and an integrated and continuous care based on empathy by favoring early detection of palliative needs, adapting treatments and resources, effective communication and, at the same time, controlling symptoms efficiently. Thus, we can argue that PC management should be included since the very beginning by considering the patient as a person and giving prominence to all those aspects that would help control symptoms. Other aspects, such as affective communication, should also be included for a close patient-health staff relationship. In this context, the quality of integrated care for patients could be improved by helping them to face the different scenarios that they could experience. ${ }^{4}$

On the other hand, palliative care requires values, so it is important to remember that in order to provide care one has to start with oneself, that is, with one's own being. These values are: empathy, compassion, humanism, efficiency, commitment and sensitivity. Developing these values requires self-interest, which would be a good start to provide quality and humane care.

When dealing with effective communication, Costa de Sousa et al. state that this is a therapeutic modality that goes beyond words and content, since it considers non-verbal signs and it is expressed through active and attentive listening, eye contact and the professional position. All of this will improve the patienthealth staff-family relationship, favoring decision-making and better social contact. Thus, health staff become a key element not only for supporting patients, but also their families. ${ }^{5}$

In this context, communication is essential when speaking appropriately to the patient by using correct expressions that do not generate more anguish than they already have because of their health. Costa de Sousa et al. point out that breaking in "bad news" plays a key role element that must be optimized when palliating, because the message delivery can generate greater anguish, since messages cause impacts, especially when they are not good news. On the other hand, good communication must encompass environments that ensure that people's needs are met, as well as encompassing their fears or insecurities, experiences and other emotions in order to minimize their fears and increase their confidence. ${ }^{1-6}$

First, it is important for health personnel to learn how to control their fears, particularly they have to stop considering death as a failure, they have to consider it as part of the finite life, as part of the end of the process of living. This is noted, because we are educated to heal, to save, and not to let go.

García-Alandete et al. state something very true, that is, suffering from cancer does not necessarily imply extreme physical deterioration, intense pain or death, since there are people who have got cured of this disease because of some 
factors such as the stage and disease progression. Regarding palliative care, the main objective is the relief of suffering, and point out something very relevant, i.e. "it is the person who suffers, not the body or the mind," so they include another essential element in palliative care: existential suffering, which has hardly been considered and within spiritual suffering is found. He also mentions a series of elements related to the PC process, which will influence in a certain way the patient's response. Among these elements are: vulnerability or fragility, which the patient is experiencing because of the illness; deterioration of the quality of life, which mainly occurs in the advanced stages of the disease; negative emotional reactions; feelings of loss, self-pity, a sense of worth and personal dignity, among other elements that will determine the interventions that should be given to the patient. Thus, if all these elements are considered since the very beginning, PC could achieve more favorable responses and better results in the CPs. ${ }^{6}$

On the other hand, it is important to consider that all patients respond differently, that is, we all have different human reactions to diseases, emotions, etc. Therefore, interventions must be individualized and focused on each of the characteristics of people with cancer or any other disease. Also, they must include their environment or, better said, their families in order to strengthen that support network around the patient. Spirituality is another element to consider for PC. Rudilla et al. claim that when spirituality is elaborated effectively, it will help the person find the meaning and accept death at the end of life. When someone is in a stage of finitude, that person sets out on a spiritual journey and then starts to experience the need to maintain hope and accept death. This point is important, because spirituality is associated with fewer suicide attempts and desires to die. And on the contrary, if this need is not met, the person may become depressed and, consequently, poor pain control occurs. $^{7}$

Similarly, in other article, Rudilla et al. mention that quality of life, which is one of the main objectives of palliative care, cannot be favored entirely if the spiritual dimension is not addressed. However, care would be incomplete because it has not been given the boom that it deserves, so this very important part of spirituality is neglected. They cannot be ignored, they are part of a whole, including physical, emotional and social aspects of the person. Some studies claim there is a relationship between spiritual discomfort and poor somatic control. Thus, spirituality is an indication of the patient's well-being and quality of life. This also emphasizes the importance it would have if all these aspects were taken into account at the beginning of the disease, that is, when diagnosing. ${ }^{8}$

In Spain, PC models are based on needs of the primary and tertiary levels of patient care. Depending on the complexity, care is delegated to the corresponding authorities. They compare needs of patients with cancer and patients without cancer according to the symptoms and how cancer patients receive palliative care. $^{9}$

Campello Vicentea and Chocarro González rightly mention that families and patients can benefit from palliative care in the early stages of the disease, not only when planning a good death, but also to benefit from any stage of the disease. Thus, curative care and palliative care are not mutually exclusive and that they can work in parallel to treat patients comprehensively by reinforcing palliative care as the disease progresses, so all the needs of the person are met since the very beginning of the diagnosis. This helps people to strengthen their spirituality and when they accept the disease, then they can have a better control of their symptoms. ${ }^{10}$

Sánchez-Pedraza et al. reinforce the above and the main theme by stating that the early provision of $\mathrm{PC}$, in addition to improving people's quality of life, also reduces health expenses and helps to clarify treatment preferences (especially when there is a good communication of the information, as mentioned above) and the goals of care. Likewise, they help improve people's quality of life, which leads to a better control of symptoms, improves the relationship between health personnel and the patient and there is greater satisfaction on the part of the patient and their families. In this study we observed that the patients had a higher level of education, which possibly helps them make decisions regarding their treatments and request palliative support. Therefore, it is also necessary to take into account all the aspects that include people in their life roles. ${ }^{11}$

As a continuation of the above considerations, León et al. show again the cost-benefit of PC. If PC was provided efficiently, the days spent at hospital would undoubtedly be reduced, in addition to having a better control of symptoms and considering that PC must be provided since the beginning of the diagnosis, while taking into account that it is not only a matter of training health professionals to provide palliative care, but also the little resource allocated for this purpose. In Mexico, despite there is legislation in the area of PC, this has not been met as it has not been given the corresponding boom. ${ }^{12}$

Antueno and Silberberg reported that patients should be referred to early palliative care, that is, since the diagnosis of the disease in order to be treated simultaneously with curative treatment, as claimed by the WHO. Antueno and Silberberg observed during interviews that patients experience the maximum pain period at the beginning of the disease because of poor communication, uncertainty and fear of dying and as palliative care treatment is provided, these feelings decrease. Therefore, we realize that it would be very interesting to include PC since the beginning of the curative treatment in order to improve quality of life of patients. $^{13}$

Lima et al. reported that a single understanding constitutes the philosophy of palliative care (humanistic approach), starting 
from care and not from healing itself. In their study on family caregivers they highlight the importance of providing comfort and making the day less painful. Faith, trust, and belief in a supreme being help caregivers cope with life being finite. The importance of a dialogue to induce resilience and coping. Likewise, they suggest that human interaction, stressful daily life, procedures and bad news are the challenges that technological advances and health professionals have not been able to overcome. Because of sociocultural characteristics and worldview of people, there is no exact formula to treat the emergent desires of cancer or any other disease. ${ }^{14}$

Further studies like the previous one would also help us explore those elements that play a key role in sick people and their families so that they are treated since the disease is diagnosed. The support network has always been vital at the beginning of any disease, if only the support was, as mentioned throughout this paper, provided from the beginning of the diagnosis, as well as monitoring curative treatment, there is no doubt that better coping mechanisms would be achieved in relatives and patients. However, this assistance support is lacking in the field of health. ${ }^{15,16}$

Andrés et al. point out that PC begins with the diagnosis of the disease and continues to grief, so a qualified multidisciplinary team is needed and must be prepared for interaction and dedication to both patients and their families. They also claim that there is no single place where palliative care can be provided, the most appropriate is where the patient needs this care, that is, at home, at the hospital, in a long-term care center or at any other health care service unit. ${ }^{15}$

Cancer is undoubtedly a disease predominating among noncommunicable chronic diseases, which also cause high costs for public health and, of course, it progresses so fast. In addition to physical changes, functional disability, vulnerability and limitations experienced by young people who are developing a chronic disease prove to be transformative and decisive in the face of social exclusion and loss of functionality within this process of being sick. This process limits the human being to plan the future by blunting him or her and inhibiting questions about their disease. Gomes Gouvea uses the Palliative Performance Scale (PPS), which is a validated tool that offers major aspects to be considered, since knowing the predictions may indicate the intensification needed for care. In this context, providing palliative care since diagnosis is recommended. Providing curative treatment since the beginning along with the necessary interventions so that, according to progress of the disease, PC can replace curative medicine until the moment that only PC meets the physical, emotional, social and spiritual needs of the patients and their families, even in mourning. ${ }^{16}$

Thus, it is important to highlight that there are certain characteristics that will allow palliative care to be carried out correctly and that also depends on the human responses that can be generated when communicating with the staff. Thus, the importance of including all the fundamental aspects that comprehend PC is reinforced, which is an integrated way of seeing the person, as a whole, in all aspects, taking him or her into account as of the diagnosis.

In a nutshell, the problem is also that health personnel are not really qualified to provide palliative care and there are very few personnel dedicated to this area. For example, medical personnel, since the beginning of their training, have perceived death as a failure and certain thoughts like this do not help accept that life is finite, which leads to other circumstances. In a certain way, a little more acceptance of this moment occurs among the nursing staff, because of their direct contact with the patient, which helps them accept situations where there is no more choice. However, we are also educated to cure, but not to heal, so it is also difficult for us to help others deal with this process during that moment.

\section{CONCLUSIONS}

Most of the articles mentioned herein state the parts that must be mixed when providing palliative care. However, diverse situations, such as schooling, access to services, characteristics of the disease and the person, sometimes cause that the care is not provided properly. We usually focus on the functional and physical part of the person, leaving aside spirituality, emotions, feelings, listening, and other factors that complement palliative care, which undoubtedly help patients to have a better quality of life from diagnosis and the start of treatment.

On the other hand, health personnel are taught that palliative care is primarily focused on the final part of the disease, there is no focus since the beginning of diagnosis. Thus, it would be very helpful for patients to include palliative care in curative care especially when the life of a young person is altered in its vital and social functionality by a chronic and degenerative disease. Additionally, costs of care would likely decrease if palliative care was provided properly. Therefore, it is evident that these domains must be complemented: bio-psycho-social and spiritual that allows to perceive people as a whole and in this aspect palliative care must be included in the diagnostic phase to help patients and their families to improve decision-making and life quality.

\section{REFERENCES}

[1] World Health Organization (WHO), 2021. Cancer Today. International Agency for Research On Cancer (IARC). The Global Cancer Observatory (GCO). Available on: https://gco.iarc.fr/ [Accessed on July 8 2021].

[2] World Health Organization (WHO), 2020. Cancer. Palliative Care. Available on: https://www.who.int/news-room/factsheets/detail/palliative-care / [Accessed on July 8 2021].

[3] Castôr KS, Moura ECR, Pereira EC, Alves DC, Ribeiro TS, Leal P da C. Palliative care: epidemiological profile with a biopsychosocial look on oncological patients. Braz. J. Pain 2019; 2(1): 49-54. 
[4] Mejías Estévez MJ. Cuidados Paliativos y Atención Primaria: integración o nuevo paradigma. Medicina de Familia. SEMERGEN. 2019; 45 (5): 285-7.

[5] Souza FAC, Borreli A, Fernandes MA, Costa SFGD, Andrade CG, Andrade FF. Scientific production in oncological palliative care with emphasis in communication. Rev. Assoc. Med. Bras. (1992). 2020; 66(10): 1455-60.

[6] García-Alandete J, Hernández-Jiménez MJ. El sufrimiento existencial en el paciente oncológico en estadio avanzado: dimensiones y ejes vertebradores para la intervención psicológica. Persona Bioética 2018; 22(2): 319-30. C

[7] Rudilla D, Oliver A, Galiana L, Barreto P. Espiritualidad en atención paliativa: Evidencias sobre la intervención con counselling. Psychosocial Intervention 2015;24 (2);79-82.

[8] Rudilla D, Soto A, Pérez MA, Galiana L, Fombuena M, Oliver A et al. Intervenciones psicológicas en espiritualidad en cuidados paliativos: una revisión sistemática. Med. Paliat. 2018;25(3):203-12.

[9] Priego-Valladares M, González de la Aleja García-Luengo P, GarcíaNavarro M del M, Tello-Valero A, Portilla-Sogorb J, RamosRincón JM. Diferencias en pacientes oncológicos y no oncológicos ingresados en una unidad de cuidados paliativos de reciente creación en un hospital de tercer nivel en la Comunidad Valenciana (España). Med. Paliat 2018;25(3):130-5.

[10] Campello Vicente C, Chocarro González L. Necesidades de cuidados paliativos en enfermos no oncológicos con enfermedad crónica avanzada: una revisión sistemática. Med. Paliat. 2018;25(2):6682.

[11] Sánchez-Pedraza R, Sierra-Matamoros F, Morales-Mesa OL. Relación entre calidad de vida y Provisión de cuidado paliativo en Mujeres con cáncer en colombia: Un estudio transversal. Rev. Colomb. Obst. Ginecol. 2017; 68 (1): 25-34.

[12] Ximena León M, Quijano M, Romero M, Salamanca N, Sánchez O, Ortegón A, et al. Costos directos del cuidado paliativo domiciliario para pacientes con cáncer gástrico estadio IV en Colombia. Univ. Méd. 2016; 57 (3): 294-306.

[13] Antueno P, Silberberg A. Eficacia de los cuidados paliativos en el alivio del sufrimiento. Persona Bioética 2018; 22 (2): 367-80.

[14] Lima L de ES, Santana ME de, Correa Júnior AJS, Vasconcelos EV. Experiencias de cuidadores familiares de pacientes oncológicos en cuidados paliativos / Juntos resistimos, aparte caemos: experiencias de cuidadores familiares de pacientes oncológicos en cuidados paliativos. R. Pesq. Cuid. Fundam. Online 2019; 11(4): 931-6.

[15] Andrés SC, Machado LB, Franco FP, Santos DS dos, Torres RF, Pedroso SU. Nursing care for patients in palliative care. Res. Soc. Develop. 2021; 10 (6): e55910616140.

[16] Gomes Gouvea MP. The need for palliative care among patients with chronic diseases: a situational diagnosis in a university hospital. Rev. Bras. Geriatr. Gerontol. 2919; 22 (05): e190085. 